\title{
Hashtag Campaigning as an Act of Resistance: A Micro-linguistic Analysis of Eleven Twitter Hashtag Campaigns $(*)$
}

\author{
Supervised by: \\ Professor Amani Badawi \\ Associate Professor RANDA ANWAR \\ Faculty of Arts, Cairo University
}

\section{Amira Hanafi Elzohiery \\ Assistant Lecturer, Department of English Language and \\ Literature, Cairo University}

\begin{abstract}
Investigating the micro-linguistic patterns of the discourse of the internet helps in understanding how users employ certain linguistic conventions to deliver their messages. However, no research has been conducted to analyze Twitter hashtag campaigning as a distinctive genre with definite micro-linguistic features (i.e., the morphological and syntactic levels). Thus, it was significant to investigate how this genre enables and enhances collective action through the choice of certain linguistic features. This study utilized Casañ-Pitarch's new multi-model of genre analysis (2017) to analyze the micro-linguistic features of hashtag campaigning that qualify it to be a distinctive genre. Through employing this model, the study adopted a mixed method approach to analyze a corpus of 33,000 tweets written in English from top trending hashtag campaigns during 2016-2018. These hashtags included \#BlackLivesMatter, \#NeverTrump, \#TimesUp, \#Metoo, \#NetNeutrality, \#SaveAleppo, \#MakeAmericaGreatAgain, \#YemenInquiryNow, \#FeelTheBern, \#InternationalWomensDay, and \#NeverHillary. Using manual analysis and methods of corpus linguistics, a genre analysis was conducted in terms of the morphological features of these hashtags. The analysis showed that the hashtags campaigns varied in the choice and the frequency of the morphological features used in each campaign. Although the selected hashtag campaigns belonged to the same genre and had one communicative purpose, this purpose was achieved through reporting information only or interaction with the readers.
\end{abstract}

(*)Hashtag Campaigning as an Act of Resistance: A Micro-linguistic Analysis of Eleven Twitter Hashtag Campaigns, Vol. 10, Issue No.1, Jan. 2021, pp.9-46. 


\section{Keywords}

Twitter, Hashtags, Hashtag Activism, Digital Genres, Genre Analysis, Online Campaigns

الملخص

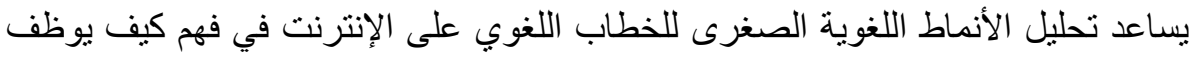

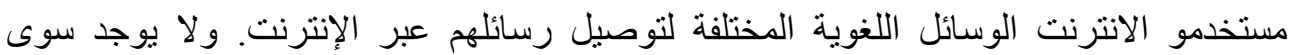
در اسات لغوية قليلة لبحث كيف يستطيع مستخدمو تويتر القيام بحملات الهاشتاج المختلفة سواء الاجتماعية والسياسية و الانسانية من خلال كتابة مجمو عة من التغريدات. وبالتالي ، كان من المهر

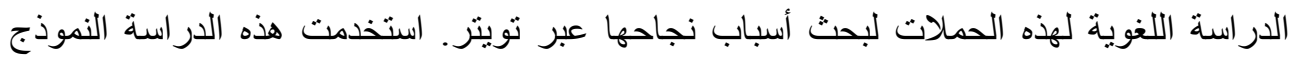

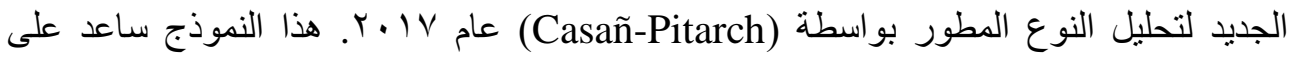

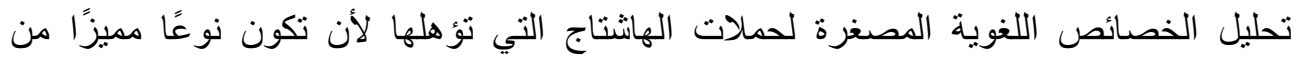

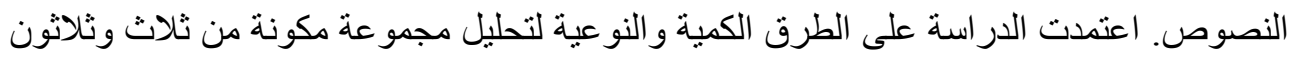
ألف تغريدة مكتوبة باللغة الإنجليزية على تويتر، وذللك من خلال أكثر احدى عشر حمله للاعثتاج

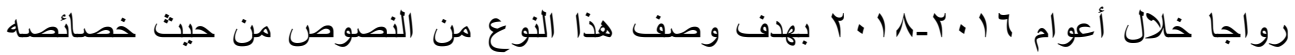
اللغوية المعجمية. وباستخدام تطبيقات المخزون اللغوي، أظهرت النتائج إن الحملات كانت منباينة في اختيار الخصائص المعجمية النحوية المستخدمة في كل حملة. و اظهرت ايضا أن على الرغم من

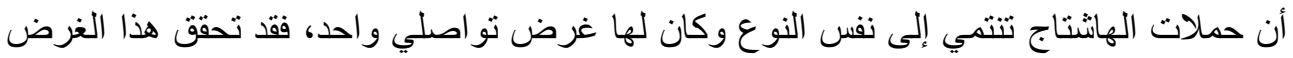
من خلال توصيل المعلومات فقط أو التفاعل مع القراء.

الكلمات المفتاحية

تويتر، النصوص الرقمية، الحملات الالكترونية، هانتاج، تحليل النوع، التغريدات، تحليل

النصوص

\section{Introduction}

In 2007, the self-described micro-blogging service, Twitter, was launched. The platform's main idea was based on this concept of posting short-formed updates from large and diverse networks of strangers or friends. On Twitter, the connections between users "are not bidirectional, but they reflect an individual's attention to others, who may or may not reciprocate connection or attention" (Lomborg, 2013, p. 101). Now, Twitter has 326 million monthly active users (Grothaus, 2018). Narratives on the platform took a different form from other blogging services due to the 
nature of Twitter as a micro-blogging service where the users had to express their ideas in less than 140 characters in length in order to write a single tweet. In 2017, Twitter doubled the character count for tweets to reach 280 characters. This makes the nature of any tweet extremely special, for it expresses condensed discourse that might not follow the rules of typical narratives. In addition, Twitter makes it easy for many users to read hundreds of posts in a short amount of time.

One of the distinctive features that characterized Twitter at its beginning was that it allowed its users to write the \# symbol followed by a word or a phrase to create hashtags. According to Zappavigna (2011), "hashtags are an emergent convention for labeling the topic of a micro-post and a form of metadata incorporated into posts" (p.3). Twitter users can use hashtags relevant to the topic of their tweets, and these hashtags can be accessed by anyone to follow any topic on Twitter. Lomborg (2013) contended that now mastering the use of the hashtag signals mastering Twitter as a digital medium. Remarkably, the use of hashtags via Twitter has marked a genuine "functional shift in the history of this symbol" (Heyd \& Puschmann, 2016, p. 5). Despite the digital preexistence of hashtags, it is through the context of social media post-2005 that the hashtag and the digital linguistic practice of hashtagging have become established in the public awareness. In 2009, Twitter granted the practice of hashtagging its official status by adding clickable hashtagged lexical items to make them searchable. Then, hashtags have turned into conversation markers and indexing system tools to store, search for, and collect information on Twitter. Since hashtags can be viewed as "topical markers, an indication to the context of the tweet or as the core idea expressed in the tweet" (Tsur \& Rappoport, 2012, p. 644), they have been utilized by multiple Twitter users to contribute to the topic and add similar or related content at any time. In 2010, Trending Topics were added to the Twitter homepage to monitor the mechanism of hashtag popularity in real time. Recently, hashtags have spread to other platforms such as Instagram, Facebook, Pinterest, Tumblr, and YouTube.

Now, the creation of campaigns is usually launched through 
hashtags; however, not all hashtags are utilized to create campaigns, publics, or maintain communities (Rambukkana, 2015). Hashtag campaigning can be defined as the act of fighting for or supporting a cause that people are advocating through social media like Facebook, Twitter, Instagram, Tumblr, and other networking websites. It creates awareness around vital issues in the offline world or the online world via social media. Therefore, it has changed the way people can have their voice expressed.

In addition, the hegemonic ideology of the internet is revolving around two main concepts: empowerment and freedom (Demata, Heaney, \& Herring, 2018). Hashtags can be considered one of the strategies that users employ to achieve and propagate the two concepts. This is because Twitter users employ hashtags to express their ideologies, thus, creating their hashtag campaigning. Although several researchers used to call hashtag campaigning armchair activism done by the residents of the keyboards, slacktivism, online echo-chambers (Bastos, Mercea, \& Baronchelli, 2018), or an empty online effort, there has been a growing body of literature that suggests that hashtag campaigning is increasingly indispensible and complementary to offline efforts (Ofori-parku \& Moscato, 2018). Also, there has been a growing body of literature that is trying to study and analyze the distinctive features of hashtag campaigning.

\section{Literature Review}

Genre analysis has rocketed as a useful tool for investigating the development of online communication forms since the public breakthrough of the internet (Lomborg, 2013). Genre analysis is also highly useful for understanding how users create and navigate digital genres. Additionally, it frames the conventions and expectations of those users. Genres can be defined as "a class of communicative events that share some set of communicative purposes" (Swales, 1990). In order to identify and describe these communicative purposes, it is necessary to analyze the form, the content, and the functionality of this genre. Swales also noted that a genre is usually named and recognized by members of the culture in which it is found. This analysis is known as genre analysis which started at the beginning to analyze different academic genres. 
Following Swales' steps, Vijay K. Bhatia (1993) expanded Swales' (1990) explanation on genre analysis by defining the notion of a nonfictional genre. His starting point was the definition by Swales, and he then added that the nature of a genre "is primarily characterized by the communicative purpose(s) that it is intended to fulfill" (Bhatia, 1993, p. 13). In this regard, the communicative purpose(s) will determine the structure of the genre. Bhatia continued his elaboration with the observation that "communicative purpose is a fairly reliable criterion to identify and distinguish sub-genres" (Bhatia, 1993). Although Swales and Bhatia agreed on the nature of a genre, they disagreed on the idea that communicative purposes would guide the analyst towards a possible difference between genres, whereas Swales showed that other factors were also important in the connection between genres.

In order to perform a genre analysis, according to the previous concepts, the analysis of a text should not focus only on the informational content of the text as such but on the features and generic conventions used which can make the text similar to other texts that belong to the same genre. At the beginning, their application of genre analysis was limited to the pedagogical context, communication training, or consultation. For example, they analyzed the introduction, methods, results, discussion, and conclusion of research articles.

Bhatia (2004) stated that the constant change in media and globalization is reconfiguring the ways texts are produced and perceived. Hence, genre analysis should be applied to include other new emergent mediums that appeared such as emails, homepages, websites, brochures, blogs, and any other form of new oral communication. He redefined genre analysis as "a multi-disciplinary activity used to determine the form of any particular type of text and to help individuals reproduce them with the correct choice of lexicon and grammar" (Casañ-Pitarch, 2017).

In 2017, Casañ-Pitarch developed his model based on Bhatia's definition of genre analysis (2004) as a multi-disciplinary activity used to "determine the form of any particular type of text and to help individuals reproduce them with the correct choice of lexicon and grammar" (Casañ-Pitarch, 2017, 236). The aim of the model was to analyze, describe, and reproduce genres 
through analytical research of either oral or written discourse forms. It is composed of two levels: the macro-textual level and micro-textual level.

\section{A- The Macro-structure Analysis}

It should include the quantification of forms, structures, moves, steps forming the genre.

\section{B- The Micro-structure Analysis}

It includes the analysis of language typology, morphological formality, terminology, $\quad$ verbs, personal pronouns, and syntax.

\subsection{Studies on Web-based Genres}

It is clear that digital genres have borrowed several features from the paper world; therefore, the majority of studies concluded that the new genres drew upon the conventional genres besides the new emergent genres. Concerning the studies conducted on web-genres, there has been a number of studies during the past two decades that analyze the form and the content of web-genres. It began when Dillon and Gushrowski (2000) analyzed home pages as a new genre with distinctive features using genre analysis. Their findings claimed that the personal web page might be the first digital information genre. Mehrpour and Mehrzad (2013) conducted a comparative genre analysis of English business emails in terms of their generic and lexico-grammatical levels. They compared 60 English business emails written by Iranians with the same number of emails written by native English speakers. They followed the framework of genre analysis proposed by Swales (1990), Bhatia (1993), and Sonto's (2002). The results indicated that Iranian and native English business correspondents were similar in their generic structures to exchange information. Similarly, Zarei and Darani (2013) conducted a genre analysis study on 200 spam emails, 100 English and 100 Persian emails received by the researchers in Iran from an online supplier over a period of ten weeks. The researchers adopted the framework used by Bhatia (1993) on structural analysis of service spam emails. The researchers stated that some moves proposed by Bhatia (1998) appeared to be obligatory while others appeared to be optional. Recently, Sagun and Luyt (2017) examined the Singaporean print culture through the genre 
analysis of a bookstore Facebook page. The findings revealed the page carried some structural features that were not present in similar genres on Facebook.

\subsection{Articles Written on Hashtag Activism on Twitter}

A number of articles discussed hashtag activism on Twitter such as Hayes's article (2017) which brought to light how Twitter has been transformed into a public space for protest and not only a way of circulating news and data. Similarly, Clark's article (2016) on hashtag feminism illustrated how hashtag activism has become a powerful tool for fighting gender inequities around the world. Rentschler (2015) elaborated on the controversy around the popular hashtag \#safteytipsforladies. She explained how Twitter helped the hashtag resonate by indicating women response to rape culture. Likewise, Williams (2015) argued in her article how feminists of color resisted violence with hashtag feminism. In 2014, Megarry also addressed the online abuse women receive through the analysis of the Twitter hashtag \#Mencallmethings. However, the study neither analyzed the structure nor the discourse of the feminist hashtags. Also, the researchers did not use statistical data to support their argument.

\subsection{Empirical Studies on the use of Hashtags on Twitter}

Concerning the empirical studies conducted on the use of Hashtags on Twitter, Trillo's study (2017) focused on analyzing the content features of the hashtag campaign: \#SayNoStopVAW which was launched by the European Commission in 2016 for the elimination of gender based violence. However, the hashtag gathered limited contributions. Pang and Law (2016) also analyzed the content features of one hashtag which was \#WorldEnvironmentDay. Allem et al. (2016) conducted a case study on the efficiency of Twitter as a campaigning tool, and they based their research on the campaign launched by the California Department of Public Health. Likewise, Adi (2015) analyzed the content and the conversation tools around the \#publicrelations and \#pr hashtags on Twitter. She stated that Twitter has become a sphere for community building and a media outlet for both institutional settings and social movements, and that the most 
informative tool was Twitter's hashtagging. Maity, Ghuku, Upmanyu, and Mukherjee (2015) were engaged in a study that quantitatively analyzed both the word level as well as the hashtags of Twitter as they investigated the use of formal and informal expressions on Twitter. Moreover, Wikström (2014) explored the communicative functions served by hashtags on Twitter from a pragmatic perspective. Furthermore, Page (2012) compared the frequency, types and grammatical context of hashtags in a dataset of 92,000 tweets between distinctive groups such as corporations and celebrities and some 'ordinary' users of Twitter. She also tried to document the evolving use of Twitter by these groups over time.

\subsection{Empirical Studies on Twitter from a Linguistic Perspective}

Several researchers categorized Twitter as a relatively new medium and embarked on analyzing its prevalent discourse and content; however, a few studies have explored Twitter discourse from a linguistic perspective. As for the application of genre analysis on Twitter, Shaffer, Freund, and Welch (2013) conducted a small-scale genre analysis study on the tweets of the Canadian Federal government. The results suggested that the government's account on Twitter served as a public relations tool. Using content analysis, Hu, Talamadupula, and Subbarao (2013) investigated the linguistic and comparative methods for analyzing linguistic style and psycholinguistic features of Twitter. Therefore, they compared the style of Twitter with the style of SMS, chat, email, blogs, and newspapers. Their analysis revealed that Twitter's language was more conservative and less informal than SMS and online chat. Also, Twitter users started to develop their unique linguistic styles. For example, both first-person and thirdperson pronouns were extensively used, whereas other mediums tend to utilize fewer pronouns. In addition, Twitter's usage of tenses was similar to SMS and chat. Moreover, the language of Twitter appeared to be constantly changing and dynamic although its users tended to imitate the linguistic practices of traditional media. In 2015, Dayter delved deep into the structure of the narrative forms on Twitter and illustrated how they differed from the prototypical narrative structure based on the Labovian structure. The analysis showed how the traditional dimensions of a narrative were 
reshaped in the context of Twitter. Coesemans and De Cock (2017) explored how language was employed on Twitter by the Belgian and Spanish politicians in the context of the 2014 European elections. They investigated three interrelated aspects of political communication on Twitter: How political candidates adapted their language to the technological constraints of Twitter, which linguistic strategies politicians use to express self-reference, and how some of the image building strategies can be interpreted as reflexive signs of meta-pragmatic awareness. The study concluded that politicians adapted their self-reference strategies to the technological constraints of Twitter. The more politicians tweeted about themselves, the more exposure they got and so their chances to be followed online.

It appears from the previous review of literature that since the rate of technological advancement is increasing with time, linguists are trying to find new ways of how to adapt the conventional theoretical frameworks to the new mediums that are available now. A great variety of digital genres are born, and they present new challenges of how to define and explore them in the light of the traditional typologies. Several linguists attempted to linguistically explore these web-based genres such as emails, homepages, forums, blogs, and micro-blogs. They investigated the language and the structure patterns presented in micro-blogging services such as Twitter, but a few studies conducted a genre analysis of tweets. No studies have attempted to investigate the genre of hashtag campaigning in terms of their micro-linguistic features especially their morphological features.

\section{Aim of the Study}

The study investigates the micro-linguistic features (i.e., morphological features) surrounding hashtag campaigning on Twitter through top trending hashtags that endorse social, political, and humanitarian causes. The main objective of the study is to find out whether the tweets written through these top hashtag campaigns in 2016, 2017, and 2018 constitute a genre and have a shared communicative purpose. 


\section{Research Questions}

The study focuses on analyzing tweets written in top trending hashtags, and the main research question of the study is:

Does hashtag campaigning on Twitter represent a distinctive genre in terms of its micro-linguistic features?

The main question is broken down into the following sub-questions:

a- What are the similarities and differences between the hashtag campaigns in terms of their micro-linguistic features?

b- What is the effect of the theme of each hashtag campaign on the choice of its morphological markers (i.e., nominalization, pronouns, conjunctions, prepositions, adjectives, and negation)?

\section{Methodology}

\subsection{Sample}

Using manual analysis and tools of corpus linguistics, a mixedmethod design approach was applied, involving collecting and analyzing both qualitative and quantitative data in some phases during the research process. The researcher collected 33,000 tweets (written in English) from public Twitter accounts using eleven of the top trending hashtag campaigns on Twitter. These campaigns were used to propagate political, social, and humanitarian causes from January, 2016 until January, 2018. Each selected hashtag campaign included the top 3,000 tweets during the active life-cycle of the campaign (the campaign can last for months). The researcher chose five political hashtag campaigns, and they were \#BlackLivesMatter, \#FeelTheBern, \#MakeAmericaGreatAgain, \#NeverHillary, \#NeverTrump; and two humanitarian crisis campaigns: \#SaveAleppo and \#YemenInquiryNow. In addition, four social hashtag campaigns were explored \#Metoo, \#InternationalWomensDay, \#TimesUp, and \#NetNeutrality.

\subsection{Description of the Tweeps}

The participants in this study were tweeps from all over the world who wrote their tweets in English. However, the study did not take into consideration their gender, nationality, cultural, or educational background. 


\subsection{Hashtag Campaigns}

\#BlackLivesMatter (2016)

The theme of \#BlackLivesMatter in 2016 revolved around the US presidential elections as the movement made a prominent appearance in the elections.

\section{\#NeverTrump (2016)}

\#NeverTrump was another opinionated political hashtag campaign that was associated with the US 2016 presidential elections. The \#NeverTrump was one of those anti-Trump hashtags, which started as a movement with different names such as The Stop Trump Movement, The Anti-Trump, Dump Trump, or The Never Trump Movement. "Concerns about Trump's experience, intelligence, ideological convictions, and controversial statements led several voters join the movement" (Johnson, Mccray, \& Ragusa, 2018).

\section{\#Metoo (2017)}

\#Metoo was a social hashtag campaign that appeared publically in 2017 when the actress Alyssa Milano started a hashtag campaign on Twitter to invite those who have experienced sexual harassment to respond with "Me too" imitating her. By the end of November 2017, Twitter confirmed that over 1.7 million tweets had been posted with hashtag reaching 85 countries, a Twitter spokesperson informed CBSN (Television Broadcasting Company) news (Park, 2017).

\section{\#Timesup (2018)}

Although the hashtag campaign \#Timesup was similar to \#Metoo in its social aim, the hashtag focused on the sexual harassment and racial injustice that take place in a male dominated work-place.

\section{\#NetNeutrality (2018)}

It is a social hashtag campaign that propagated free internet for all people. . "Net neutrality is the idea that internet service providers should treat all content following their cables and cell towers equally" (Finley, 2018). 
\#SaveAleppo (2017)

\#SaveAleppo was a humanitarian crisis hashtag campaign that aimed at informing readers all over the world of the carnage that was happening in Syria.

\section{\#MakeAmericaGreatAgain (2016)}

\#MakeAmericaGreatAgain was a political pro-Trump hashtag campaign that aimed to convince readers of the necessity to elect Trump who would save America again. Trump depicted America "as a decadent and apocalyptic wasteland" that needed his leadership (Mukherjee, 2018). His supporters embraced his ideas as well and attempted to persuade other tweeps of his political agenda.

\section{\#YemenInquiryNow (2016)}

\#YemenInquiryNow was the second crisis campaign in the present data that aimed to bring awareness of the humanitarian crisis in Yemen. Multiple tweeps used the hashtag to criticize the policy of what they called "the Saudi-led coalition" that caused disproportionate casualties. They also used the hashtag to post horrific images and videos of children suffering from severe malnutrition.

\section{\#FeelTheBern (2016)}

\#FeelTheBern was the fifth political campaign in the hashtag campaigns supporting Bernie Sanders, the 2016 US political candidate.

\section{\#InternationalWomensDay (2016)}

\#InternationalWomensDay was the fourth social hashtag campaign, but it aimed towards celebrating women and their rights. Several Twitter users posted the hashtag to tweet about the impact of women on their lives, women's rights, and gender equality.

\section{\#NeverHillary (2016)}

\#NeverHillary was the sixth political hashtag campaign which was created by Trump supporters and joined by Bernie's as well, who stated that they would rather vote for Donald Trump than Hillary Clinton. 


\subsection{Data Analysis}

Each hashtag campaign was analyzed separately. Initially, the researcher chose one hashtag campaign to analyze it manually to see the whole picture of the studied phenomenon and identify the micro-linguistic features that were needed to be investigated. During that primary observation, the researcher gained insights of the next steps of the analysis. The second phase of the analysis was analyzing the micro-linguistic features of the tweets.

\subsection{Casañ-Pitarch (2017) AMS Model}

The study utilized a recent modified model based on Bhatia's model (1993): the Analysis of Multi-genre Structures (AMS) model developed by Casañ-Pitarch (2017). The model was adopted in the study because it offered a detailed description of the lexico-grammatical features that could be investigated in any text whether it is written or spoken. The model was divided into two parts: the macro-linguistic analysis of the tweets and the micro-linguistic analysis of the tweets. According to Casañ-Pitarch (2017), the macro-textual analysis should determine the number of words, sentences, moves, and steps in the text-genre (which are out of the focus of this study), whereas the micro-level analysis includes a series of features in morphological and syntactic levels: morphology, type of language, terminology, syntax, and verbal tenses (p. 239). Some features in the model were dropped out because they were redundant or rare in web-texts. In the following paper, the analysis focuses on the morphological features of hashtag campaigning.

\section{Micro-level Analysis: Lexico-grammatical Analysis}

To pinpoint the lexico-grammatical features of hashtag campaigns, a micro-level analysis of the tweets was conducted.

\section{Morphological Analysis}

Using AntConc, the study examined the morphological composition of the genre which included the investigation of different word categories such as nominalization, pronouns, prepositions, conjunctions, and negation. 
Concerning adjectives, the researcher used UAM (Version 3.3; O'Donnell, 2017) corpus tool to investigate all instances of adjectives; moreover, she used Simple Concordance Program (a software that searches natural language text files for words, phrases, and patterns) to track all the adjectives that end with derivational suffixes. Also, to investigate all instances of negative prefixes such as de-, dis-, in-, mis-, non-, un-, ir-, antiand il-, the researcher used Simple Concordance Program. However, the program made some mistakes, so the researcher had to manually revise the results. This manual investigation was necessary to remove all the confusing words.

\section{Nominalization}

Fowler, Hodge, Kress, and Trew (1979) showed that utilizing nominalization in texts is always indicative and ideologically charged. Therefore, the morphological analysis focused on one type of nominalization which happens at the level of the word through the formation of nouns by adding suffixes (e.g., -tion, -ment, -ness, -ity, -sion, ship, -ism, -ist, -acy, -ance) to other nouns, verbs, or adjectives whereas the formation of nominalization through noun phrases was investigated through the syntactic analysis.

\section{Pronouns}

According to $\mathrm{Hu}$ et al. (2013), "the most widely-adopted grammar measure is the usage of personal pronouns" (p. 246). Also, Brown and Gilman's pioneering study (1960) showed that the choice of pronouns is affected by the relationship between the speaker and the listener. Therefore, it was necessary to investigate the use of pronouns in all hashtag campaigns.

\section{Conjunctions}

This study explored three types of conjunctions: coordinating conjunctions (e.g., and, but, so, yet, for, or), conjunctive adverbs (e.g., moreover, therefore, however etc.), and subordinating conjunctions (e.g., that, if, whether, because, although, when, as if, in order that, as long as, etc.). 


\section{Amira Hanafi Elzohiery}

\section{Prepositions}

The study investigated the most common short prepositions and excluded most of the two-word prepositions and multi-word prepositions.

\section{Adjectives}

In the present study, adjectives were categorized according to their morphological criterion: derivative adjectives (i.e., derived from a verb or a noun) and non-derivative adjectives.

\section{Negation}

The present study investigated instances of negation through sentence level and word level through negative morphemes such as de-, dis-, in-, mis-, non-, un-, ir-, anti-, and il-

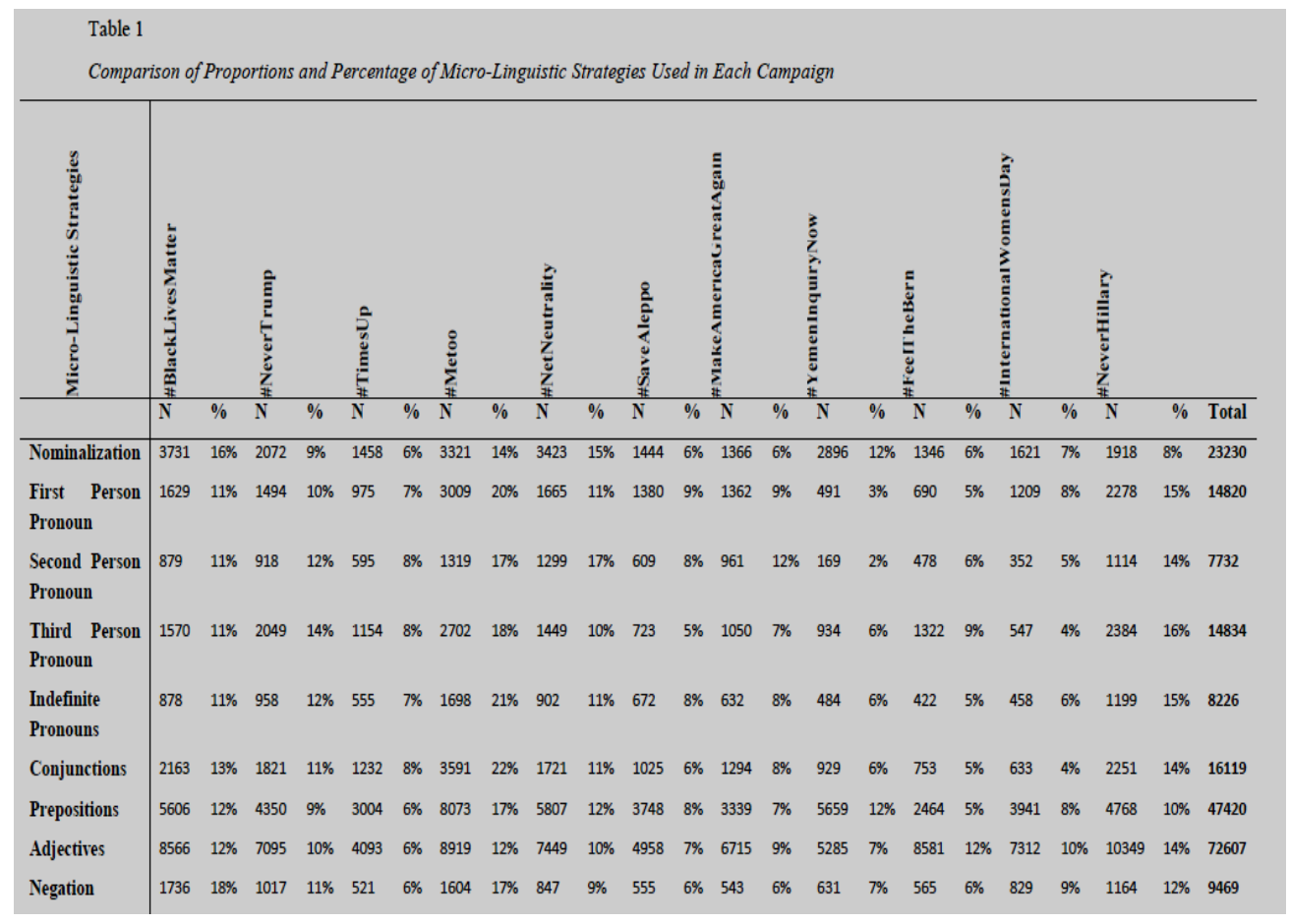




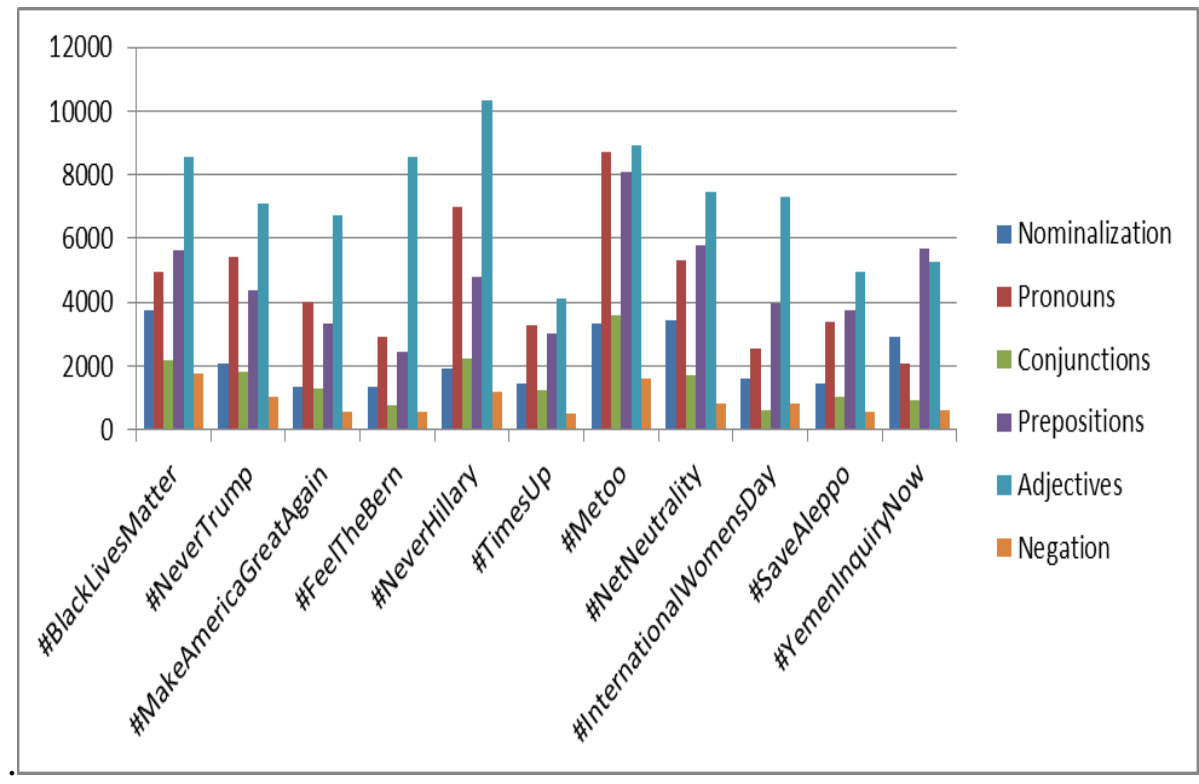

Figure 1. Comparison between the eleven hashtag campaigns in terms of their Morphological Features

\section{Analysis and Discussion}

In order to answer the first research sub-question on the similarities and the differences between the eleven hashtag campaigns in terms of their morphological markers, a comparison was conducted between all campaigns to summarize all the morphological features used in the campaigns (See Table 1 and Figure 1).

\subsection{The Morphological Analysis}

\subsubsection{Nominalization}

Table 1 illustrates that instances of nominalization were most posted in the two campaigns: \#BlackLivesMatter and \#NeverHillary (3731 instances for each) forming $16 \%$ of all instances of nominalization in all campaigns. \#NetNeutrality ( $\mathrm{n}=3432)$ and \#YemenInquiryNow $(\mathrm{n}=2896)$ had less frequent instances. Nominalizations were least posted in the campaign \#FeelTheBern (1346 instances).

It is suggested that the tweeps endeavored to focus on the result or 
the action of the verb rather than the verb itself or the agent. Fowler et al. (1979) stated that by means of nominalization, "processes and qualities assume the status of things: impersonal, inanimate, capable of being amassed and counted like capital, paraded like possessions" (p. 80). They gave the example of a text referring to 'allegations' rather than stating $\mathrm{X}$ alleged that $\mathrm{Y}$ did $\mathrm{A}$. According to this view, instead of specifying the verb of the action / state, its tense, its modality, or the participants of this verb, all information is concealed to present the nominalized process as the truth. This transformation can be manipulated to hide some information of the story that the tweeps advocate and highlight other parts that endorse their ideology. In the present study, this information may be "easily inferred by the readers in some cases, but in others, the text may be said to affect readers' comprehension of events in an ideologically significant way" (Lingle, 2017, p. 11). This might help in mobilizing more participants towards the hashtag campaigns, who might feel sympathetic, supportive, or provoked by the outcome of the action. For example, that was obvious in \#YemenInquiryNow where words such as "starvation", "coalition", "investigation", "obstruction", "mobilization”, "formation", "politicization”, "execution", "malnutrition", "extinction", and "education" were utilized to shed light on the consequences of the actions rather than the agent or the social actor. In addition, by turning verbs into nouns, "speakers/writers can convey that the entities, denoted by nominalization, have a real and necessary existence" (Billig, 2008, p. 789).

Similarly, that was the case in \#NetNeutrality as words such as "action", "legislation", "destruction", "resolution", "communication", "corruption", "information", "inflation", "implementation", "destruction", or "connection" were used to convey the outcomes of net neutrality so as to invite Twitter users to defend net neutrality and take action. Notably, the word "action" itself occurred 106 times in this hashtag campaign. In \#Metoo, words related to the theme of campaign such as "accusation", "conversation", "flirtation", "predation", “interaction", "manipulation", "discrimination", "humiliation", "conviction", "molestation", “emasculation", "corruption", or "publication” were repeated several times. 
For example, in a tweet that said: "We are making a stand. Men, Women, Children should be safe from Rape, Assault and Molestation", the writer of the tweet focused on nouns more than the agents or the verbs. It seems it was not necessary to mention the tense, time, modality of the verb since they were implicitly understood. Additionally, according to the Billig (2008), "if speakers / writers used nominalization, they can transform statements that identified agents of actions into agentless statements that convey less information" (p.7). Therefore, it could be suggested that nominalization fits the nature of Twitter as the text is bound to the space it occupies while it tries to cover all the necessary points. In addition, the act of implicating information is convenient to the communal aspect of hashtag campaigns; users tend to post in the campaign as if they belong to one community that has its shared conventions and references.

\subsubsection{Pronouns}

\section{First Person Pronouns}

Table 1 shows that first person pronouns were most used in the campaign \#Metoo (3009 instances) accounting for $20 \%$ of all instances of first person pronouns in all campaigns. This was followed by \#NeverHillary (2278 instances) and \#NetNeutrality (1665 instances). First person pronouns were least used in the campaign \#YemenInquiryNow (491 instances).

\#Metoo had the highest frequency of first person pronouns as the campaign included several highly personal and intimate stories that triggered the use of first person pronouns. Users preferred to talk more about their personal experience not their friends' or relatives'. That contributed to the trustworthiness of the anecdotes against sexual harassment shared in this campaign as multiple Twitter users believed in the aim of the campaign, and they were encouraged to share their stories as well. \#NeverHillary and \#NetNeutrality followed in the list although the campaigns did not include several personal stories. It seems that the participants used the first person pronoun to convince other users to take part in their campaigns by adding credibility to their tweets. 
Here are some occurrences of "I" in \#Metoo, \#NeverHillary, and \#NetNeutrality:

1- I am chocked up a little bit but I am finally coming out to tell my story.. \#Metoo

2- They look at me as if I am weak or pathetic but they are wrong I am so much than my trauma.. \#Metoo

3- It has been five years and I am still scared to show his name.. \#Meetoo

4- I am still dealing with depression over it, 8 years later, sadly.. \#Metoo

5- I am among the millions outraged. Seriously.. \#NetNeutrality

6- I am still pissed @AjitPaiFCC and @version for net neutrality being removed.. .. \#NetNeutrality

7- Oh, am I allowed to say corrupt @ HillaryClinton is corrupt or that sexist because she is a woman.. \#NeverHillary

8- I am with Trump still \#NeverHillary

In \#NetNeutrality, many users preferred to create involvement with other users since the decision of net neutrality would affect all of them as internet users. Interestingly, the most used pronouns in \#NetNeutrality were "I" and "We". The use of "we" in this controversial campaign gave a sense of collectivity and shared responsibility as users referred to the end of net neutrality as the end of the internet as "we know it". Because the hashtag campaign urged Twitter users to sign a petition and join the battle to save net neutrality, users needed to illustrate that they did not speak from their own perspective but from a collective perspective as well. That shortened the distance between the readers and the participants as the use of "we" made them feel they shared the same goals and circumstances. These findings agree with Rezapour's (2018) who suggested that pluralism increased in tweets after remarkable events where users prefer to use the pronoun "we" instead of "I". First person pronouns had the lowest frequency in the campaign \#YemenInquiryNow because in this campaign, users did not need to talk about themselves; they tweeted more about what was happening in Yemen. This means that the theme of the campaign has an 
influence on the choice of the pronouns that can include or exclude the reader of the tweet, as well as, separate self from other.

\section{Second Person Pronouns}

Also, Table 1 reveals that, as expected, the majority of second person pronouns occurred in the campaign \#Metoo (1319 instances) forming 17\% of all instances of second person pronouns in all campaigns. \#NetNeutrality (1299 instances) and \#NeverHillary (1114 instances) had less frequent second person pronouns, respectively. Second person pronouns were least used in the campaign \#YemenInquiryNow (169 instances).

The use of the second person pronouns such as "you" fits the nature of hashtag campaigns as it can address anyone, and it lets the addressee feel the responsibility that $\mathrm{s} / \mathrm{he}$ is part of the campaign, and possibly s/he has a role to play in this campaign. \#Metoo had the highest percentage of the pronoun "you" because the pronoun was employed for multiple purposes. Examples of these purposes from the sample are:

9- If you don't call racism out after witnessing it, then you are guilty by complicity and association \#Metoo

10- Please RT if you're a strong Woman (or Man) but care equally for Kids rights too! Hello Hollywood, R U Listening? \#Metoo

11- @Oprah You sicken me with your false outrage \#Metoo

12- We see you. We hear you. And we will tell your stories. \#Metoo

13-Silence is not consent. Consent is explicit and obvious. If you are not sure if your partner is comfortable, ask. \#Metoo

In Example 9 and Example 10, the writer invited other Twitter users to be positive and take action in the \#Metoo campaign through the use of "you". The expression "RT if you" in Example 10, which stands for "Retweet if you", is usually common in Twitter campaigns in order to popularize the message of the campaign quickly through Twitter by asking other users to resend it. "You" can be a tool for emotional manipulation. In the previous examples, the writer utilized emotional manipulation by using the words "strong", "guilty" and "kids" with the pronoun "you" to affect other users and appeal to their emotions. They used the adjective "guilty" to 
make other non-active users feel responsible for staying silent and not participating in the campaign. "You" was also used in rhetorical questions such as "Hello Hollywood! R U Listening?" to emphasize the idea of the tweet. Another function of "you" is that it helps users talk directly to famous figures, politicians, and celebrities as in Example 11 that was directed to the Twitter account of Oprah Winfery. The pronoun "you" can be a tool for offering compassion and solace and making users sense they are not alone as in Example 12 where "you" was repeated two times to emphasize this notion. Also, the pronoun is used for giving advice related to the issue of the campaign as in Example 13.

\#NeverHillary and \#NetNeutrality followed in the list of second person pronouns. This usage of the second person pronouns fosters a sense of rapport between Twitter users, which makes the online campaign similar to a face-to-face conversation or a heated debate. According to Grieve, Biber, Friginal, and Nekrasova (2010), the use of pronouns implies that "the reader is in the same basic frame of reference as the author" (p.308). Moreover, through the use of second person pronouns, the user feels s/he can truly voice his/her perspective towards the common controversial issues, thus, enhancing the interactional and conversational nature of some hashtag campaigns.

\section{Third Person Pronouns}

Third person pronouns were most used in the campaign \#Metoo (2702 instances) as they made up $18 \%$ of all instances of third person pronouns in all campaigns. This was followed by \#NeverHillary (2384 instances) and \#NeverTrump (2049 instances). Third person pronouns were least tweeted in the campaign \#InternationalWomensDay (547 instances).

The use of pronouns emphasizes the narrative-descriptive aspect of some hashtag campaigns, yet not all hashtag campaigns were characterized by that narrative-descriptive style. In \#Metoo, users employed "it" to refer to the same shared reference, which corroborated the highly narrative and conversational style of the campaign (See Figure 2). The employment of "it" is "associated with generalized and inexplicit references" (Grieve et al., 
2010, p. 210). Additionally, it is suggested that tweeps preferred to use "it" to connect all the tweets in the campaign to each other since they all revolved around the same topic which was sexual harassment. Being interwoven, the tweets in the hashtag campaign resembled a colossal conversation thread where millions of users could take part and express their notions towards the campaign explicitly. Although each tweet seemed to be a separate text in itself, once the participants of the campaign annotated their tweet with the hashtag of the campaign, they realized that they joined the conversation and became a member of the community of the campaign. Therefore, when they used "it", they knew that what they were talking about could be easily identified. Also, in \#Metoo, "it" was used as a euphemism for "sex", "harassment", and "rape" in some tweets. This idea reinforces the unseen ties that bind users together to their shared reference; thus, it emphasizes their group identity. \#FeelTheBern and \#NeverHillary followed \#Metoo. The pronoun "it" was repeated in \#FeelTheBern because several supporters used the catch phrase "Feeling it", which was related to the slogan of the campaign "Feel the Bern". It meant that they felt Bernie Sanders in their hearts.

The two pronouns: "they" and "he" followed in the list of top third person pronouns utilized. \#Nevertrump had the highest frequency of the pronoun "he" since it referred to Donald Trump, and the pronoun reference was in the hashtag itself. This may be indicative of the reduced lexical text that is suitable to the short messages of Twitter. It is noticeable that the three campaigns: \#InternationalWomensDay, \#SaveAleppo, and \#YemenInquiryNow had fewer numbers of pronouns as the campaigns were less narration-focused. The high usage of first and third-person pronouns on Twitter is consistent with the findings of previous research (e.g., Naaman, Boase, \& Lai, 2010; and Hu et al., 2013) who reached similar results that first and third person pronouns on Twitter dominated the use of other pronouns. 


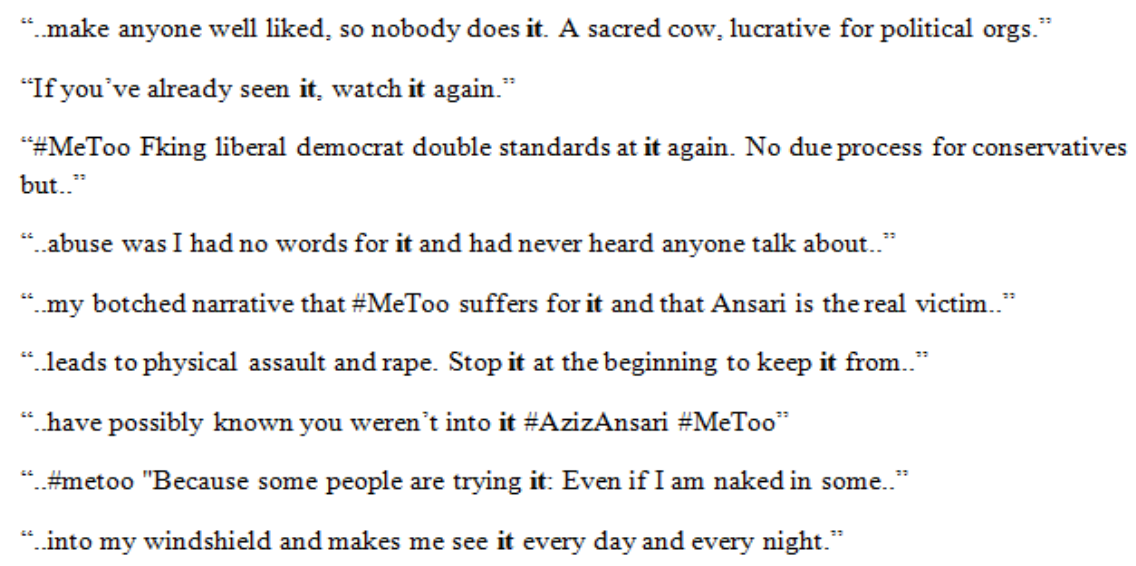

Figure 2. Some selected lines of the use of "it" in \#Metoo

\section{Indefinite Pronouns}

Table 1 reveals that \#Metoo had the most number of indefinite pronouns (1698 instances) as it made up $21 \%$ of all instances of indefinite pronouns in all campaigns. \#NeverHillary (1199 instances) and \#BlackLivesMatter (878 instances) followed it. \#FeelTheBern was the campaign with the fewest indefinite pronouns (422 instances).

The high use of the indefinite pronoun "all" reflected the sense of collectiveness that the hashtag campaigns tended to propagate (See Figure 3). It had the highest frequency in the most interactional campaign \#Metoo, emphasizing the communal sense of collectiveness and togetherness in the campaign. It also happened in \#NeverHillary and \#BlackLivesMatter but with fewer frequencies. In \#BlackLivesMatter, the tweeps used the pronoun "all" (in these examples, it was used as a determiner) as a tool for inclusiveness and emphasis. In some tweets, the pronoun "all" was written in uppercase letter to imply shouting and frustration. Similarly, the pronouns "one" and "many" were employed as generic pronouns that did not refer to anyone in particular. This occurred in examples such as "I am the only one?", "my perpetrator is the only one", and "not a single one" in \#Metoo. 
Hashtag Campaigning as an Act of Resistance: A Microlinguistic Analysis of Eleven Twitter Hashtag Campaigns

\author{
terToo \#BlackLivesMatter \#AllLivesMatter \#JUSTICE4 ALL \#AGM The @NFL Chose to Tank \\ victim of police brutality while y' all \#All LivesMatter headasses defended the cop. Now \\ you at?!???? Trump is working for all Americans. \#MAGA https:// twitter.com/josephlawle \\ in fact an inalienable right of all Americans regardless of race or creed! \\ more mistaken. With LIBERTY \& JUSTICE for ALL Americans!! \#TakeAKnee \#BlackLivesMatter" @Dines \\ for the equality and dignity of all Americans. \#VetsAgainstTrump \#BlackLivesMatter pi \\ \#BLACKLIVESMATTER \#LGBTQ FREEDOM AND EQUALITY TO ALL \#AMERICANS @YaNative @usembassyjkt @USEmbassyCair \\ for the equality and dignity of all Americans."' Yes, and thank you! Thank \\ 's make this book pop y' all and bring attention to the matter \\ \#MarchForlmpeachment \#MarchOnDC2018 must include all anti-Trump groups from \#BlackLivesMatter to \# \\ efore the \#WhiteMan engaged in \#AfricanSlaveTrade all \#ArabicNations had been for thousands of \\ boy @JoynerLucas Y'all say y' all are liberal"" or "'traditional"" but really
}

Figure 3. Selected concordance lines for the use of "all" in \#BlackLivesMatter

\title{
6.1.3 Conjunctions
}

Conjunctions were most used in the campaign \#Metoo (3591 instances) forming $22 \%$ of all instances of conjunctions in all campaigns, followed by \#NeverTrump (1821 instances) and \#NeverHillary (2251 instances). \#InternationalWomensDay (633 instances) had the fewest numbers of conjunctions.

The top used conjunction was the coordinating conjunction "and" because it was convenient to the casual style of writing on Twitter (See Figure 4), which was similar to conversational interactions. This agrees with the findings of Biber et al. (2000) on the use of coordinators, which indicated that "and" is by far the most common coordinator in all the registers" (p. 77).The users refrained from using the two-word conjunctions and conjunctive adverbs because these conjunctions are more associated with formal texts, and they require a degree of complexity in writing. However, the data under investigation were mostly composed of structurally simple and brief sentences. The use of "and" is simple, and it does not need sophisticated writing skills as it connects between two simple sentences, nouns, or phrases. Biber et al. (2000) studied coordinators across different varieties of English mainly conversation, fiction, newspaper language, and academic prose, and they called "and" a simple coordinator. The coordinating conjunction "and" suits the narrative style of \#Metoo and the interactional nature of \#BlackLivesMatter and \#NeverHillary. 
The subordinating conjunction "if" and the coordinating conjunction "but" followed in the list. Similar to "and", they do not need challenging writing skills, which fits the brevity that characterizes Twitter. According to Grieve et al. (2010), who conducted a multimodal analysis on the styles of weblogs, they found that "if a text discusses numerous disparate ideas and topics, perhaps it is particularly necessary to explicitly connect these ideas through high loading of casual coordination and conjuncts" (p. 319). In comparison, in the present study, the tweets in hashtag campaigns focused on one concise idea; thus, the participants in the campaign usually did not resort to complex conjunctions to merge two ideas or more. They used direct and concise sentence structures so as to catch readers' attention quickly. This makes the form of the tweets more similar to the conversational style than writing because writing is usually characterized by lexical complexity (Halliday, 1985).

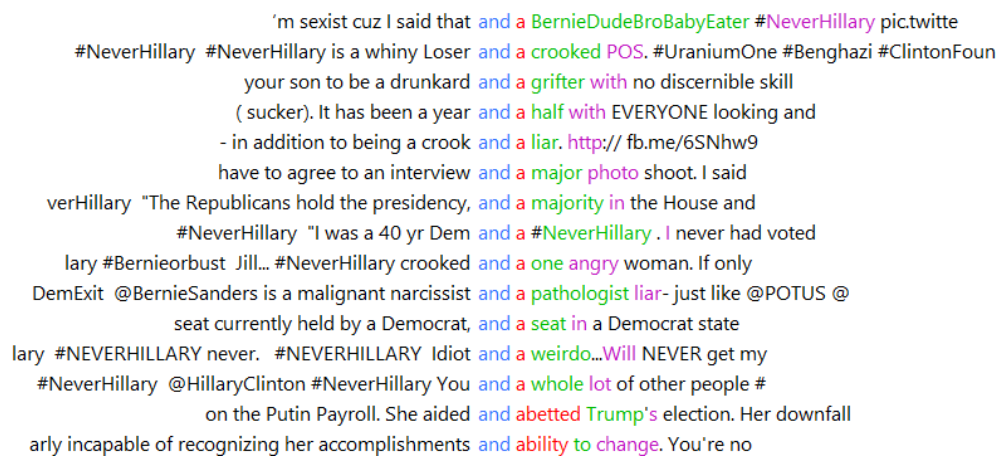

Figure 4. Selected concordance lines for the use of "and" in \#NeverHillary

\subsubsection{Prepositions}

As for prepositions, they dominated the campaign \#Metoo forming 17\% of all instances of prepositions in all campaigns (8073 instances). \#NetNeutrality (5807 instances) and \#BlackLivesMatter (5606 instances) followed it. \#FeelTheBern had the lowest proportion of prepositions (2464 instances).

Prepositions enhance information of manner, time, direction, or location of 
the posts, which was convenient for the reporting of events in hashtag campaigns such as \#Metoo, \#BlackLivesMatter, \#NetNeutrality, and \#YemenInquiryNow. The four campaigns had the highest frequency of prepositions. The top used prepositions in the hashtag campaigns were respectively: of, in, for, to, on, with, by, and at. It is noticeable that there were simple not compound prepositions (i.e., composed of more than a single word). "Of" was the top used preposition, which was used for belonging, connection, or reference, for example, a record of abuse, the feet of the abusers, survival of actual rape, voice of any female, and customers of any genders \#Metoo. This agrees with the findings of Kennedy (1998) on the basis of Sinclair's (1991) pilot analysis of the large Birmingham corpus that the most frequent preposition of all English prepositions is "of". Similarly, Biber et al. (2000) also concluded that "of" was the most used preposition across the different varieties of English mainly conversation, fiction, newspaper language, and academic prose. This makes it rather more of a feature of the English language as a whole not a specific feature of hashtag campaigns, which indicates that hashtag campaigns do not adopt innovative ways in the use of prepositions.

\subsubsection{Adjectives}

It is clear from Table 1 that the majority of adjectives occurred in the campaign \#NeverHillary (10349 instances) forming 14\% of all of adjectives in all campaigns. Adjectives occurred less frequently in \#Metoo (8919 instances) and \#FeelTheBern (8581 instances). Adjectives were least used in the campaign \#TimesUp (4093 instances).

\#NeverHillary had the highest proportion of adjectives such as right, great, good, bad, and crooked. This was followed by \#FeelTheBern where the top used adjectives were: free, available, right, good, and criminal. It was noticeable that the majority of adjectives utilized were attributive (premodifiers of nouns) rather than predictive. Also, it was evident that derivative adjectives were less frequent than other forms of adjectives that were composed of one morpheme. The reason behind that was that users tended to write their tweets in a simple and concise way rather than 
resorting to suffixation or derivation. They needed to modify the nouns used, add information, and fit their thoughts in one single tweet (with 140 character limit).

\subsubsection{Negation}

As it can be seen in Table 1, negation tools were more frequent in the campaign \#BlackLivesMatter (1736 instances) forming 18\% of all instances of negation in all campaigns, followed by \#Metoo (1607 instances) and \#NeverHillary (1164 instances). Instances of negation were the least frequent in the campaign \#TimesUp (521 instances).

The findings indicated that instances through negation at sentence level $(n=5153)$ outnumbered instances of negation on word level $(n=4895)$ although the difference was quite slight. The particle "not" was the most frequent tool of negation, which meant that the negation of clauses dominated all other instances. This agrees with the findings of Biber et al. (2000) on the use of "not" across different registers and the findings of Duran (2018) on the use of negation in political discourse. Some examples are:

14-\#TakeAKnee is NOT about respecting veterns and you know it.

\section{\#BlackLivesMatter}

\section{5- War IS NOT A GAME. \#NeverTrump}

16-I forced myself to walk through the abuse step by step so I did not forget that I was not a liar.. \#TimesUp

17-Sex is not the problem. Sexism is the problem. \#Metoo

18- We see you! You are NOT BACKING \#NetNeutrality FOR THE PEOPLE. YOU WILL NOT BE REELECTED. \#NetNeutrality

19- It is not ok for this to continue. \#SaveAleppo

20- It is not a lie. It is a DUTY. \#MakeAmericaGreatAgain

21-All the Security Council Resolutions did not include war against Yemen. \#YemenInquiryNow

22-I am with her. NOT \#FeelTheBern

23-Suspicious deaths should not be in vain.

\section{\#InternationalWomensDay}

24- You SHOULD NOT BE IN OFFICE. \#NeverHillary 
The examples illustrate that most of the instances of "not" were to declare a clear, overt stance towards a certain argument. In Example 23 and Example 24, the tweeps used the modal "should" with "not", which made the tweet resemble authoritative discourse. The use of the uppercase letters even corroborated this idea as their use has become an internet code for loudness, screaming, and authority. Interestingly, the word "not" was written in uppercase letters. Participants think that by using uppercase letters and the particle "not", they have the power to virtually scream and shout to convey the significance of their points of view. Also, it is possible that they needed to make their messages flash out and be typographically visible. That was evident in Examples: 14, 15, 18, and 22. For the previous reasons, the most interactional campaigns had the highest frequency of negation; \#Metoo had the highest numbers of instances of negation, followed by \#NeverHillary and \#NetNeutrality. It is worth mentioning that in \#NeverHillary, the hashtag itself included the adverb of negation "never". In Examples: 14, 15, $17,19,7$, and 22, the use of "not" with the present copula "be" emphasized how the discourse of users embodied an act of power because it seemed that they believed they were stating facts that could not be refuted. They did not even use mitigating adjectives or adverbs to downplay their negative stances.

\section{The Influence of The Theme of Each Hashtag Campaign on the Choice of the Micro-Linguistic Features}

This section answers the second research sub-question by explaining how the theme and the communicative practices of each hashtag campaign can influence the choice and the frequency of its micro-linguistic features. It was noticeable that while the hashtag campaigns were similar in their communicative purpose which is propagating a certain cause, some variance across their micro-linguistic features existed, and this can be linked to whether the hashtag campaign adopted a political, humanitarian, or social cause. This, consequently, had an effect on the campaigns' degree of being interactional or informational (See Figure 5). On one hand, the more the micro-linguistic features employed in a campaign, the more interactional the campaign was. On the other hand, the less micro-linguistic features utilized 
in a campaign, the more informational the campaign was. The following section explains this idea in detail.

\section{\#BlackLivesMatter}

The hashtag campaign's political main aim triggered the use of the highest number of instances of nominalization and negation.

\section{\#NeverTrump}

The political campaign was characterized by the high use of third person pronouns, indefinite pronouns, conjunctions, adjectives, and negation. The use of the third person pronouns was due to the fact that multiple tweets were about Trump and his ideology or other candidates' as well. Users employed adjectives for the same purpose. They also tended to write indefinite pronouns such as "all "and "many" to emphasize the collectivity of their situation in order to persuade other users that their tweets did not represent a single perspective of its user, but "all" users adopted their point of view as well. They utilized conjunctions to connect their ideas and negation to assert their political situation.

\section{\#Timesup}

Although the hashtag campaign \#Timesup was similar to \#Metoo in its social aim, the users of the campaign did not heavily resort to the same linguistic features they used in \#Metoo. Probably, they felt that the function of \#Timesup was only to raise awareness of the legal support women could receive if they were seeking justice for sexual harassment in the workplace. The campaign had the lowest use of adjectives and instances of negation. It is suggested that the aim of this campaign was informing rather than persuading. Users believed that the initial step of convincing users to take part in this movement had happened first in \#Metoo.

\section{\#Metoo}

\#Metoo can be considered the most interactional campaign of all hashtag campaigns in the sample. Users made use of the utmost of microlinguistic features to persuade other Twitter users of their cause. It included the highest numbers of first person pronouns, second person pronouns, 
third person pronoun, indefinite pronouns, conjunctions, and prepositions. Participants used to share their personal detailed stories using the first person pronoun and stories of others as well using third person pronouns and indefinite pronouns. They invited other users to participate using the pronoun "you", and they employed "we" to make readers feel safe that they all shared the same problem. The high use of conjunctions and prepositions was necessary to add details to their personal accounts of harassment.

\section{\#NetNeutrality}

This social campaign included information about the concept of net neutrality and its effects rather than personal stories. Regarding its morphological analysis, the campaign had a high number of second person pronouns and prepositions. Writers needed to urgently engage other users by using the pronouns "you" and "we". Additionally, it had fair instances of nominalization that showed the influence of net neutrality.

\section{\#SaveAleppo}

The humanitarian campaign aimed at informing readers all over the world of the carnage that was happening in Syria; however, the campaign did not include remarkable micro-linguistic findings.

\#MakeAmericaGreatAgain

The political campaign had a high number of second person pronouns to encourage users to vote for Donald Trump.

\section{\#YemenInquiryNow}

Similar to SaveAleppo, participants in this campaign resorted to a few micro-linguistic features to convey their messages. Concerning the micro-linguistic analysis, the campaign had a high use of nominalization to illustrate the deadly consequences of the war in Yemen. Prepositions were used heavily too.

\section{\#FeelTheBern}

The political campaign involved a high use of adjectives that 
described Sanders, Trump, or Clinton (e.g., blind, corrupt, fat, crooked).

\section{\#InternationalWomensDay}

In this social campaign, the participants shared less micro-linguistic features than other campaigns because the participants in the campaign were inclined into celebrating the day using short sentences. Therefore, the campaign had the least numbers of conjunctions.

\section{\#NeverHillary}

The political hashtag was highly interactional because users depended heavily on the use of pronouns, conjunctions, and instances of negation. The majority of adjectives occurred in this campaign. It is suggested that the participants in this campaign joined the online war against Hillary's supporters and resorted to all the possible linguistic devices to win this war.

Interactional

Informational

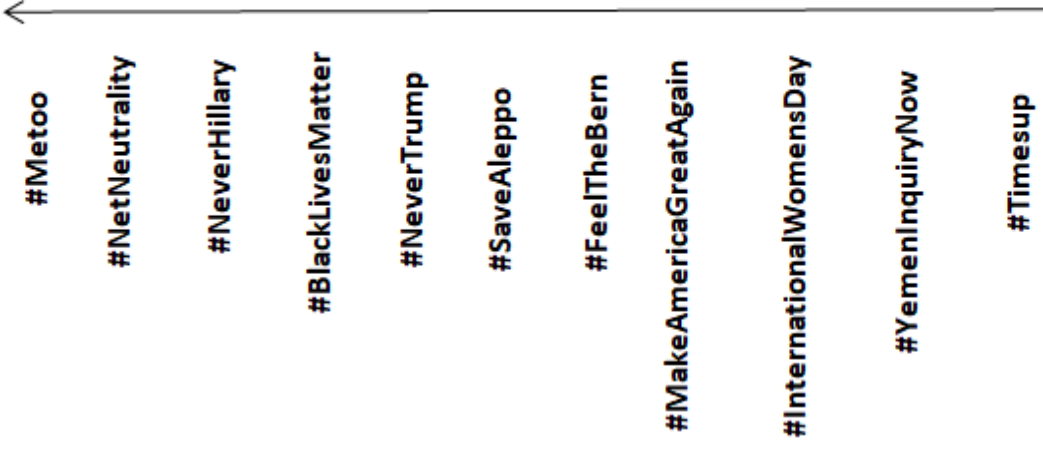

Figure 5. Degree of interaction and information in the hashtag campaigns of the study

\section{Conclusion}

The main objective of the present study was to find out whether the tweets written through the top resistance hashtag campaigns in 2016, 2017, 
and 2018 constitute a genre and have a shared communicative purpose. Although there have been multiple studies during the past two decades that analyze the form and the content of web-genres, few studies were conducted to investigate the micro-linguistic features of hashtag campaigns as one genre. According to Martin (1992), in any text, the author has particular objectives, and through the choice of specific linguistic features, the author aims at realizing these objectives. These linguistic features are crucial to understanding the framework of any specific text. Therefore, the study investigated the salient micro-linguistic choices and strategies that characterized each identified hashtag campaign, along with the reasons underlying such choices. Consequently, the study adopted the AMS framework devised by Casañ-Pitarch (2017) on genre analysis. The study concentrated on one level of analysis of Casañ-Pitarch's framework, which is the morphological analysis. In order to answer the first research subquestion on the similarities and the differences between the eleven hashtag campaigns in terms of their morphological markers, a comparison was conducted between all campaigns to summarize all the morphological features used in the campaigns.

Firstly, the results indicated that Twitter users tend to resort to distinctive morphological features, but these features differed in their frequencies. Instances of nominalization were most posted in the two campaigns: \#BlackLivesMatter and \#NeverHillary. First person pronouns, second person pronouns, third person pronouns, indefinite pronouns, conjunction, and prepositions were most used in \#Metoo. As for adjectives, the majority of adjectives occurred in the campaign \#NeverHillary Negation tools were more frequent in the campaign \#BlackLivesMatter.

Secondly, the analysis revealed that Twitter users used nominalization because it suited the goal of campaigns that focused usually on the result of the verb "the nominalized entity", which was useful in drawing attention to the influence or the effect of the process rather than the verb itself. In addition, multiple tweeps resorted to first person pronouns because self-mentioning is one of the tools that make readers more engaged with the text they are reading. The pronoun "you" was utilized as a tool for 
offering compassion and advice. As for third person pronouns, they were employed to reinforce the unseen ties that bind users together to their shared reference; thus, it emphasizes their group identity. The indefinite pronoun "all" was heavily used emphasizing the communal sense of collectiveness and togetherness in the campaign. The top used conjunction was the coordinating conjunction "and" because it was convenient to the casual style of writing on Twitter. As for adjectives, they were utilized to provide details of nouns when used attributively. The analysis also unraveled that the particle "not" was the most frequent tool of negation, which meant that the negation of clauses dominated all other instances.

Thirdly, although the hashtag campaigns three different themes (i.e., political, social, and humanitarian), the previous analysis indicated that they shared a principal communicative purpose which was promoting and propagating a certain cause. This purpose was usually consolidated by interactional tweets with the readers or intense informational tweets. However, the theme of each campaign influenced how Twitter users choose their micro-linguistic features. The more interactional the campaign is, the more inclined Twitter users to utilize several micro-linguistic features.

The findings agree with Bhatia's notion on unfamiliar genres that one genre might include overlapping communicative purposes and practices. In the present study, the authors of the tweets were mostly Twitter users; therefore, they were, according to Swales' definition (1990), part of a professional discourse community that was aware of the conventional linguistic features of the genre. The theme of each hashtag campaign directed their choices of these conventional micro-linguistic features. This makes hashtag campaigns represent a new genre that has been developed from earlier generic forms from current existing genres. This new genre is characterized by distinctive micro-linguistic features which help in boosting the nature of resistance in hashtag campaigns. 


\section{References}

Aarts, B. (1997). English syntax and argumentation. Interaction Series. Springer: Cham.

Álvarez, I., \& Muñoz, A. (2012). An insight into Twitter: A corpus based contrastive study in English and Spanish. Revista de Lingüística y Lenguas Aplicadas, 7, 37-50.

Anthony, L. (2018). AntConc (Version 3.5.7) [Computer Software]. Tokyo, Japan: Waseda University. Available from http://www.laurenceanthony.net/software . (2015). TagAnt (Version 1.1.0) [Computer Software]. Tokyo, Japan: Waseda University. Available from http://www.laurenceanthony.net/software

Bastos, M., Mercea, D., \& Baronchelli, A. (2018) The geographic embedding of online echo chambers: Evidence from the Brexit campaign. PLoS ONE, 13(11): e0206841.

Biber, D. (1988). Variation across speech and writing. New York: Cambridge University Press.

. Johansson, S., Leech, G., Conrad, S., \& Finegan, E. (2000). The Longman grammar of spoken and written English. Essex: Pearson Education Limited.

Billig, M. (2008). The language of critical discourse analysis: the case of nominalization. Discourse \& Society, 19 (6), 783-800.

Bhatia, V. K. (1993). Analyzing genre - Language use in professional settings. UK: Longman,

London.

. (2004). Worlds of written discourse: a genre-based view. London: NY Continuum.

Brown, R., \& Gilman, A. (1960). The pronouns of power and solidarity. In T. Sebeok (ed.) Style in Language. Cambridge, Massachusetts: MIT Press. 253-76.

Casañ-Pitarch, R. (2017). A proposal for genre analysis: The AMS model. EPiC Series in Language and Linguistics, (2), 235-246. 
Clark, R. "Hope in a Hashtag: the Discursive Activism of \#WhyIStayed". Feminist Media Studies, (2016):1471-5902. DOI: 10.1080/14680777.2016.1138235

Coesemans, R., \& De Cock, B. (2017). Self-reference by politicians on Twitter: Strategies to adapt to 140 characters. Journal of Pragmatics: 116.10.1016/j.pragma.2016.12.005

Dayter, D. (2015). Small stories and extended narratives on Twitter. Journal of Pragmatics, 81, 8-20.

Demata, M., Heaney, D., \& Herring, S. (2018). Language and discourse in social media: New challenges, new approaches. Altre Modernità, I-X, 1-16.

Devitt, A. (1991). Intertextuality in tax accounting: Generic, referential, and functional. In Bazerman, C., \& Paradis, J. (Eds.), Textual dynamics of the professions: Historical and contemporary studies of writing in professional communities (pp. 336-380). Madison: University of Wisconsin Press.

Dillon, A., \& Gushrowski, B. (2000). Genres and the Web - is the home page the first digital genre? Journal of the American Society for Information Science, 51(2), 202-205.

Duran, J. (2018). A corpus study of negation and their disruptive patterns in political discourse. Letras, Santa Maria, 28(56), 15-41.

Finley, K. (2018, May 9). The wired guide to net neutrality. Wired. Retrieved from: https://www.wired.com/guide-net-neutrality/

Furht, B. (2010). Handbook of social network technologies and applications. US: Springer.

Fowler, R., Hodge, B., Kress, G., \& Trew, T. (1979). Language and social control. London: Routledge

Grieve, J., Biber, D., Friginal, E., \& Nekrasova, T. (2010). Variation among blogs: A multidimensional analysis. In: Mehler, A., Sharoff, S., \& Santini, M. (eds). Genres on the Web: Computational Models and Empirical Studies. Springer, New York, 303-322.

Grothaus, M. (2018, October 10). Twitter's Q3 earnings by the numbers. Facts Company. Retrieved from: 
https://www.fastcompany.com/90256723/twitters-q3-earnings-bythe- numbers

Halliday, M. (1995). A recent view of 'Missteps' in linguistic theory. Functions of Language, 2 (2), 36-60.

Hayes, T. "\#MyNYPD: Transforming Twitter into a public place for protest". Computers and Composition 43, (2017):118-134

Herring, S., \& Emigh, W. (2005). Collaborative authoring on the web: A genre analysis of online encyclopedias. Proceedings of the Thirty-Eighth Hawai'i International Conference on System Sciences, 38, 1-10.

Heyd, T., \& Puschmann, C. (2016). Hashtagging and functional shift: adaptation and appropriation of the \#. Journal of Pragmatics. https://doi.org/10.1016/j.pragma.2016.12.004

Hu, Y., Talamadupula, K., \& Subbarao, K. (2013). Dude, srsly?: The surprisingly formal nature of twitter's language. In Proceedings of ICWSM.

Johnson, L. R., Mccray, D., \& Ragusa, J. M. (2018). \#NeverTrump : Why Republican members of Congress refused to support their party's nominee in the 2016 presidential election. Research \& Politics, 5(1), 205316801774938. doi:10.1177/2053168017749383

Kennedy, G. (1998). An introduction to corpus linguistics. London: Longman.

Lingle, W. (2017). Nominalizations, agentless passives, and social actors mystification: Newspapers editorials on the Greek financial crisis (PhD Dissertation). University of Birmingham. University of Birmingham Research Archive.

Lomborg, S. (2013). Social media, social genres: making sense of the ordinary. NewYork: Routledge.

Martin, J. R. (1992). English Text: System and structure. Amsterdam: Benjamins. 
Megarry, J. "Online Incivility or Sexual Harassment? Conceptualising Women's Experiences in the Digital Dge. Women's Studies International Forum 47, (2014): 46-55.

Mehrpour, S., \& Mehrzad, M. (2013). A comparative genre analysis of English business e-mails written by Iranians and native English speakers. Theory and Practice in LanguageStudies, 3(12), 22502261.

Myers, G. (2010). Discourse of blogs and wikis. London: Continuum.

Mukherjee, S. (2018). Make America Great Again as white political theology. LISA online journal, XVI(2). Retrieved from: https://journals.openedition.org/lisa/9887?lang=en\#bibliogra phy

Naaman, M., Boase, J., \& Lai, C. (2010). Is it really about me?: Message content in social awareness streams. Proceedings of the 2010 ACM CSCW, 189-192.

Ofori-parku, S., \& Moscato, D. (2018). Hashtag activism as a form of political action: A qualitative analysis of the \#BringBackOurGirls campaign in Nigerian, UK, and U.S. Press. International Journal of Communication, 12, 24802502.

O’Donnell, M. (2017). UAM Corpus Tool version 3.3. Retrieved from: http://www.corpustool.com/download.html

Park, A. (2017). \#Metoo reaches 85 countries with $1.7 \mathrm{M}$ tweets. CBSNEWS. Accessed September 24, 2018. Retrieved from: www.cbsnews.com/news/me-too-reaches- 85countries-with-1-7million-tweets

Rambukkana, N. (2015). Hashtag Publics: The power and politics of discursive networks (digital formations). New York: Peter Lang

Rentschler, Carrie. "\#Safetytipsforladies: Feminist Twitter Takedowns of Victim Blaming". Feminist Media Studies 15, no. 2, (2015): 353-356. 
Rezapour, R. (2018). Using linguistic cues for analyzing social movements. Retrieved from: https://arxiv.org/pdf/1808.01742.pdf

Sagun, K.K., \& Luyt, B. (2017). Cultured and popular literary circuits on Facebook: A case study of Singaporean print culture in social media. Information Research, 22(2). Retrieved from http://InformationR.net/ir/22-21/paper746.html (Archived by WebCite ${ }^{\circledR}$ at http://www.webcitation.org/6r2QPamGx)

Shaffer, E., Freund, L., \& Welch, M. (2013).Tweeting the government: Preliminary findings from a genre analysis of Canadian federal government tweets. Retrieved from: http://works.bepress.com/elizabeth_shaffer/13/

Swales, J. M. (1990). Genre analysis - English in academic and research settings. Cambridge, UK: Cambridge University Press.

Tsur, O., \& Rappoport, A. (2012).What's in a hashtag?: Content based prediction of the spread of ideas in microblogging communities. Proceedings of the Fifth ACM International Conference on Web Search and Data Mining. 643-652.

Williams, Sherri. "Digital defense: Black Feminists Resist Violence with Hashtag Activism". Feminist Media Studies 15, no. 2, (2015): 341-344.

Zappavigna, M. (2011). Ambient affiliation: A linguistic perspective on Twitter. New Media \& Society, 13(5), 788-806.

Zarei, G., \& Darani, P. (2013). A comparative study of the rhetorical moves in spam emails: A cross-linguistic investigation between English and Persian spammers. English for Specific Purposes World, 40(14), 1682-3257. 